\title{
Review on Default risk of Trade Credit in the Supply Chain
}

\author{
Juanjuan Qin \\ School of Business, Tianjin University of Finance and Economics, Tianjin300222, China
}

\begin{abstract}
Keywords: Trade credit, default risk, supply chain.
\end{abstract}
\begin{abstract}
Research on credit risk has become one of hot issues focused by the financial industry in recent years, especially the measurement of credit risk. But the relevant researches mainly focus on the default risk of the bank financing. There are fewer researches on credit risk of trade credit financing, especially the influence of supply chain operation and coordination.
\end{abstract}

\section{Introduction}

Trade credit is provided by the buyer to sell a kind of credit, allowing the buyer purchased from the seller's goods without the need to immediately pay, is widely used among enterprises short-term financing. Trade credit is on the basis of benefit both parties, but there are also some risks, especially the financial environment is not perfect in developing countries. Trade credit risk is the trade credit sales, in which one party fails to fulfill the payment commitment and the possibility of losses to the other party, as retailers (or) customers unwilling or unable to repay loans for many different reasons. So that the supplier can't withdraw the payment and the possibility of forming stay dead account.

In reality, because many manufacturers of the trade credit are difficult to pay its accounts payable, the suppliers are facing financial distress or bankruptcy, such as the bankruptcy of general motors, China, Japan and South Korea auto parts suppliers are facing financial difficulties and business crisis. In our country, default between enterprises and trade credit risk problem has become the major obstacle of economic operation, seriously affected the enterprise capital turnover and economic benefits. The national bureau of statistics (1999) report of bad sales revenue each year to consume about $5 \%$ of China's enterprises, western institutions that, plus the recessive debts, corporate defaults in China should be more than $10 \%$. Country risk analysis report (2005) points out that our export bad debt rate 10 times in the developed countries.

Thus, default risk is that the borrowers are unwilling or unable to fulfill the payment because of various reasons, resulting in the loss of banks, investors or counterparty. Due to the credit risk, each firm should pay attention to evaluate default risk for possible gains and possible losses. Thus, in this study, we review the related study of default risk.

\section{Credit risk of bank credit}

In the field of financial research, many studies focus on credit risk quantitative methods, focusing on credit risk measurement of banks concerned, default prediction methods can be summarized into two categories.

The first is called structural research method. The four kinds of analysis model for example, the first model is a risk measurement model based on option pricing technology. Merton (1974), Blaek \& Scnoles (1973) was proposed by Longstaff \& Schwartz (1995) to expand. The second model is the default risk statistical model proposed by Tumbull\&Jarrow. The default rate is described as a single continuous movement, and the volatility of the rate of default is also considered. The credit rating of the time-varying risk function is estimated according to the credit spread. The third model which is a discrete time dynamic macro simulation model is proposed by Wilson (1997). This method is based on the historical data of macroeconomic variables and the average default rate of time series data of a multi factor model of plate construction in different countries and industries. The fourth model of risk value utilizes the enterprise credit rating, the rating migration matrix, loan default recovery rate, risk spreads and yields to calculate the enterprise value and volatility. 
The second category is called the statistical research method, the relationship model which searches default and corporate characteristic variables through the historical sample data of borrowing firms. Maddala (1983) distinguished the default and non-default loan applicants by the logistic model. Peng et al (2009) and Bai Shaobu(2010) studied the application of ordinal Logistic model ignoring the lower limit of sample requirements in the modeling process.

With the development of computing technology, aiming at the shortcomings of statistical or econometric methods, many non-parametric and nonlinear model developed, for example neural network in the prediction of credit default has been fully studied, West (2000) established five different neural network models and studied the commercial bank credit rating; Wang et al (1999, 2001), respectively used neural network and genetic programming method to measure the credit risk of commercial banks. Li and Xu (2010) used the improved BP neural network model to evaluate the credit of customers. In addition, the support vector machine is a method of artificial intelligence in recent years, and has been widely used in credit risk analysis (Yu et al, 2009).

Most of these models are used in the credit risk measurement in the bank financing. But few are about the default risk of trade credit.

\section{Default risk of Trade credit}

Many scholars do less evaluation on the trade credit risk assessment. In view of the trade credit risk assessment's characteristics of fuzzy data and the lack of data, Romaniuk and Hall (1992) studied the evaluation problem of business credit risk by using the fuzzy comprehensive evaluation method; Wang and Zhou (2006) researched on customer credit risk based on fuzzy clustering. Zhou (2004,2007) $)^{\mathrm{d}} \mathrm{did}$ the research from the aspect of credit indexes space structure and characteristics, and establishes the evaluation model of multidimensional dynamic credit based on ideal, which is a major innovation for processing different time data in the field of credit evaluation. Li (2009) utilized the credit risk degree as the criterion of trade credit risk, by support vector machine modeling method. Sun et al (2012) treated the credit decision problem of enterprise credit customers with incomplete information under the condition of random process as a state time discrete and continuous stochastic process.

Some scholars have studied the causes of trade credit risk. Burt Edwards (1997) qualitatively described how to carry out credit sales to prevent and control credit risk. Liu (2010) aiming at the research of enterprise credit risk and control method, put forward the concept of enterprise credit risk adjusted returns and its calculation method, and then got the reserved 'credit risk capital' for unexpected losses caused by the credit risk precaution. Wu (2011) established a decision-making model under the influence of the probability of default from the perspective of minimizing the cost of trade credit risk, gave the conditions of Kuhn-Tucker.

\section{Default risk of trade credit in the supply chain}

Along with the widespread use of commercial credit, many scholars do the research of supply chain inventory optimization based on the commercial credit. However, relevant study rarely considers the effect of trade credit risk on the supply chain inventory decision-making. The related literature can be divided into two categories: one is based on the inventory decision of individual enterprise commercial credit, main consideration under the trade credit of single enterprise in the supply chain inventory decision-making problem; The second is the joint of supply chain inventory decision-making based on commercial credit, mainly discusses the joint inventory management issues in the supply chain under the commercial credit.

The traditional economic order quantity (EOQ) model assumes that suppliers of goods purchaser receive immediately the full payment for goods, not considering the purchaser to provide customers of commercial credit. Goyal (1985) introduced the delayed payment in the EOQ model, and then there is a lot of scholars doing the extensions. Tsao and Sheen (2008) under the function of demand depends on the price and time, probes into the perishable product's optimal pricing, promotion and replenishment 
strategy; Soni and Shah (2008) discusses the demand which depends on the inventory levels of second order delay in payment strategy; Biswajit Sarkar (2012) discusses the EOQ model in demand and finite replenishment rate depending on the time situation. Qin (2012) studies the sloped market demand and replenishment depending on the market demand situation, to discuss the retailer's optimal order strategy under the commercial credit.

In recent years, some scholars have been aware of the impact of trade credit risk on supply chain operation. But the research on credit risk in the supply chain is not integrated, and there is no research related to business credit risk under supply chain coordination problems. Shi and Zhang (2010) made a preliminary discussion on the development of the trade credit period of the endogenous default risk. Lou and Zhang (2012) studied the establishment of the trade credit risk in the supply chain business credit and the optimal order quantity. Qin (2012) puts forward the optimum order of retail enterprises in the supply chain decisions considering trade credit risk caused by bad debts rate cases.

\section{Conclusion}

Research on credit risk has become one of hot issues focused by the financial industry in recent years, especially the measurement of credit risk. But the relevant researches mainly focus on the measurement of credit risk for bank financing. There are fewer researches on credit risk of trade credit financing, especially the influence of supply chain operation and coordination research. Therefore, the future research can be extended in the following aspects:

(1) The research of credit risk becomes one of the hot issues in the bank credit in recent years, especially the measurement of credit risk. But the research mainly focuses on the bank credit risk measurement. The research on trade credit risk is less, especially discussing the commercial operations and supply chain coordination under the influence of credit risk research less. Therefore, future study can discuss the evaluation of trade credit risk.

(2) In recent years, under the background of trade credit for supply chain inventory decision making research is relatively active. But considering the trade credit sales of trade credit risk and the influence of the supply chain inventory optimization problem is very few. Therefore, future study can discuss its influences on optimal decision in the supply chain members based on trade credit with the credit risk.

(3) Supply chain coordination problem has been the important issue in research of operations management. To explore the problem of supply chain coordination based on trade credit with credit risk is relatively small. Further study can enrich the study of the coordination problem in supply chain under trade credit with credit risk, to improve supply chain performance.

\section{References}

[1]. Bai Shaobu. Risk early warning of enterprise supply chain financing based on ordered logistic model [J].Economic Survey, 2010, 6: 66-71.

[2]. Beaver R. Marketing Prices, Financial ratios and the prediction of failure [J]. Journal of Accounting Research, 1968, 6(2): 179-192.

[3]. Biswajit Sarkar. An EOQ model with delay in payments and time varying deterioration rate [J]. Mathematical and Computer Modeling, 2012, 55(3-4): 367-377.

[4]. Black F, Scholes L. The pricing of options and corporate liabilities [J]. Journal of Political Economy, 1973, 81(3):637-654.

[5]. Burt Edwards. Credit Management Handbook [M]. Gower Publishing limited UK, 1997.

[6]. Goyal S K. Economic order quantity under conditions of permissible delay in payments [J]. Journal of the Operational Research Society, 1985, 36(4):335-338.

[7]. Jarrow R, Turnbull S. The intersection of market and credit risk [J].Journal of Banking \& Finance, 2000, 24(1-2):271-299.

[8]. Lou K R, W C Wang. Optimal trade credit and order quantity when trade credit impacts on both demand rate and default risk [J]. Journal of the Operational Research Society, 2012, 1-6. 
[9]. Li Xiaofeng, Xu Jiuping. The establishment of the BP neural network model for the comprehensive evaluation of commercial bank customer credit [[J]. soft science, 2010, 24 (2): 110-113.

[10]. Liu Guojiang. Enterprise credit customer selection and Research on risk management of credit [D]. Chengdu: University of Electronic Science and technology, 2009

[11]. Longstaff F, Schwartz E. Valuing credit derivatives [J]. Journal of Fixed Income, 1995, 5(1): 6-12.

[12]. Maddala G S. Limited-dependent and qualitative variables in econometrics [M]. Cambridge: Cambridge University Press, 1983: 13-90

[13]. Merton R. On the Pricing of corporate debt: the risk structure of interest rates [J]. Journal of Finance, 1974, 29(2): 449-470.

[14]. Peng Jiangang, Tu Haibo, He Qing, Zhou Yinghui. Application of ordered multi classification logistic model in the measurement of default probability[J]The Theory and Practice of Finance and Economics, 2009,30 (4): 2-7.

[15]. Qin Juanjuan. The three stage of economic order model of the influence of bad debt under the condition of deferred payment [J]. Management Science in China, 2012, 20 (6): 94-101.

[16]. Romaniuk V, Hall L. Decision making on credit worthiness, using a fuzzy connectionist model [J]. Fuzzy Sets and System, 1992, 48(1): 1522.

[17]. Soni H, Shah N.H. Optimal ordering policy for stock-dependent demand under progressive payment scheme [J]. European Journal of Operational Research, 2008, 184(1): 91-100.

[18]. Sun Qingwen, Zhang Qiongqiong, Chou Jingli,Wang Xiaojun. Credit risk decision model on the basis of different information acquisition $[\mathrm{J}]$. System engineering theory and Practice, 2012, 32 (1): 41-48.

[19]. Tsao Y C, Sheen G J. Dynamic pricing, promotion and replenishment policies for a deteriorating item under permissible delay in payments [J]. Computers \& Operations Research , 2008, 35(11): $3562-3580$.

[20]. Wang Chunfeng, Kang Li. Theory and practice of credit risk assessment model of commercial banks based on genetic programming [J]. Systems engineering theory and practice, 2001, 21 (2): 73-79.

[21]. Wang Chunfeng, Wan Haihui, Zhang Wei. Credit risk assessment of commercial banks based on neural network technology [J]. Systems engineering theory and practice, 1999, 19 (9): 24-32.

[22]. Wang Yinglie, Zhou Zongfang. Study on customer credit risk based on Fuzzy Clustering[C]. Risk analysis of the second annual conference of the Specialized Committee on the risk analysis of China's Disaster Prevention Association, 2006.

[23]. West D. Neural network credit scoring models [J]. Computer \& Operations Research, 2000, 27(11-12): 1131-1152.

[24]. Wilson T C. Portfolio credit risks I [J].Risk, 1997, 9(10):111-170.

[25]. Wu Yuping. The supply chain credit risk decision model based on loss minimization [J]. Journal of management, 2011, 8 (2): 289-293.

[26]. Shi Xiaojun, Shunming Zhang. An incentive-compatible solution for trade credit term incorporating default risk [J]. European Journal of Operational Research, 2010, 206(1):178-196.

[27]. Yu L, Wang S Y, Cao J. A modified least squares support vector machine classifier with application to credit risk analysis [J]. International Journal of Information Technology and Decision Making, 2009, 8(4): 697-710.

[28]. Zhou Zongfang, Chen Lin, Tang Xiaowo. Study on the credit state space structure of multidimensional dynamic credit evaluation $[[\mathrm{J}]$. system engineering theory and practice, 2007, 27 (4): 1-8.

[29]. Zhou Zongfang, Tang Xiaowo, Tai Yong. The order relation and dominant structure of credit index space [J]. Systems engineering theory \& practice, 2004, 24 (11): 9-14. 